\title{
Research Paper: The Effects of Neoprene Knee Brace on Kinetics of Knee Joint of Elite Wrestlers After Anterior Cruciate Ligament Reconstructive Surgery With Hamstring Tendon Autograft
}

\author{
Nader Nokhodchi ${ }^{1^{*}}$, Heydar Sadeghi ${ }^{2}$ Ismail Ebrahimi Takamjani $^{3}$, Ali Abbasi ${ }^{2}$ \\ 1. Department of Physical Education and Sport Sciences, Faculty of Humanities, University of Bojnord, Bojnord, Iran. \\ 2. Department of Sport Biomechanics and Pathology, Faculty of Physical Education and Sport Sciences, Kharazmi University, Tehran, Iran. \\ 3. Department of Physiotherapy, School of Rehabilitation Sciences, Iran University of Medical Sciences, Tehran, Iran.
}

Crtation: Nokhodchi N, Sadeghi H, Ebrahimi Takamjani I, Abbasi A. The Effects of Neoprene Knee Brace on Kinetics of Knee Joint of Elite Wrestlers After Anterior Cruciate Ligament Reconstructive Surgery With Hamstring Tendon Autograft. Physical Treatments. 2016; 6(3):143-148. https://doi.org/10.18869/nrip.ptj.6.3.143

doi : https://doi.org/10.18869/nrip.ptj.6.3.143

Article info:

Received: 20 May 2016

Accepted: 27 Aug. 2016
Keywords:

Neoprene knee brace, Knee joint kinetic, Anterior cruciate ligament reconstruction, Hamstring tendon autograft

\begin{abstract}
A B S T R A C T
Purpose: Anterior Cruciate Ligament (ACL) tear is a common injury among wrestlers. One of its treatments is reconstructive surgery with Hamstring Tendon (HST) autograft. This research aimed to examine the effect of neoprene knee brace on the knee kinetics variables of elite wrestlers after ligament reconstructive surgery with hamstring autograft.

Methods: The present research method is quasi-experimental with pretest-posttest design and a control group. A total of 10 elite wrestlers with average (SD) age of 26.1(2.37) years, average (SD) weight of 78.25(11.32) $\mathrm{kg}$ and average (SD) height of 174(3.6) $\mathrm{cm}$ all of whom underwent ACL reconstructive surgery with hamstring autograft 6 to 18 months prior to the present research were selected through convenience sampling method. In this research, the selected kinetic variables (ratio of the knee flexor muscles torque to the knee extensor muscles, the average peak torque, maximum power and total work of knee extensor and flexor muscles) were measured by isokinetic dynamometer Gymnex model ISO-1 at 120 degrees per second in two modes of with and without neoprene knee brace with open patella and two adjustable straps. To examine the research hypotheses, the statistical dependent $t$ test at the significant level of 0.05 was used. All statistical analyses were done by SPSS 16 .

Results: The findings of statistical tests demonstrated that using neoprene knee brace results in significant changes in the average peak torque, maximum power and total work of the knee flexor muscles and also the ratio of the knee flexor muscles torque to the extensor muscles $(\mathrm{P}<0.05)$. Nevertheless using neoprene knee brace did not create significant changes in the kinetic variables of knee extensor muscles $(\mathrm{P} \geq 0.05)$.

Conclusion: Based on the results, using neoprene knee brace could improve kinetic variables, especially knee flexor muscles in elite wrestlers after ligament reconstructive surgery. Therefore, these wrestlers after ACL reconstructive surgery through HST method and performing rehabilitation program can benefit from neoprene knee brace for improving kinetic variables of knee flexor muscles and reducing the likelihood of ligament re-injury during athletic activities.
\end{abstract}

\footnotetext{
* Corresponding Author:

Nader Nokhodchi, PhD

Address: Department of Physical Education and Sport Sciences, Faculty of Humanities, University of Bojnord, Bojnord, Iran

Phone: +98 (915) 5061028

E-mail: nadernokhodchil@yahoo.com
} 


\section{Introduction}

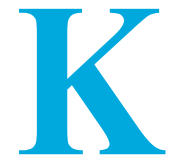

nee joint is an important part of the lower limb kinetic chain and plays a key role in bearing weight and movement. Since this joint is located between the extremity of the two long levers of tibia and femur and lacks bone stabilizer, it is vulnerable to external forces [1]. It has been estimated that knee injuries account for more than $60 \%$ of all sport injuries and Anterior Cruciate Ligament (ACL) injury alone be responsible for half of all knee injuries. Thus this injury can cause expensive treatment costs, including all of the costs related to surgery and rehabilitation program [2]. Treatment of this injury whether by operation or rehabilitation imposes a heavy cost on the individual and the society. For example, more than 300000 ACL injuries occur in the United States every year that costs more than 6 billion dollars [3].

Wrestling is one of the common reported sport activities with knee joint injuries. Studies indicate that knee injuries are among common injuries that occur in both the Free and Greco-Roman styles and ACL injury alone constitutes $20 \%$ of all knee injuries [4]. The most common surgery method for ACL tear is intra-articular reconstruction by using various grafts such as autografts, allografts, or synthetic grafts. Today, two methods of autologous bone-patella tendon-bone graft and autologous four-stand hamstring tendon graft are the most common methods of choice in ACL reconstruction and each method has its own particular advantages and disadvantages [5]. In the past 30 years, athletes have used knee braces for preventing the ACL injury and also following ACL reconstructive surgery [6]. These braces are divided into three main categories: preventive (prophylactic), rehabilitation, and functional [7]. About 55\% of physicians prescribe preventive knee brace following ACL reconstructive surgery [8]. These braces are used to treat knee joint instability resulting from dysfunction of ACL, support all ACL grafts, and also prevent ligament injury while engaged in athletic activity [9].

Neoprene sleeves are knee braces used on many occasions by athletes following reconstructive surgery [10]. Some studies show that in individuals with ACL injury, using brace alters the activity of muscles acting on knee joint. Theoret et al. (2006) reported that using brace would result in reduction of extensor muscles activities on the knee and increase flexor muscles activities [11]. However, Ramsey et al. (2003) studies demonstrate reduction in the activities of flexor muscles and increase in extensor muscles activities [12]. Nevertheless, Acierno and colleagues (1995) reported ineffectiveness of brace on knee flexor and extensor muscles activities in active individuals [13]. Also, some researchers examined the effects of wearing brace on kinetic variables. Ewing and colleagues, Morteza (2012), and Baltaci (2011) in three studies examined the effect of prophylactic braces on biomechanical variables of athletes without history of knee joint injury. In these studies which mostly employed isokinetic and field tests, results showed that using brace did not create significant changes in kinetic variables effective on athletic function such as peak torque and the work of muscles acting on the athletes' knee joint [1416]. However, several studies examined the effects of brace on kinetic variables of the athletes with ligament injury and also after reconstructive surgery.

Morteza et al. (2013) and Rebel et al. (2001) reported that using functional braces in athletes with ACL injury who had not undergone ligament reconstructive surgery would increase peak torque and muscle power $[17,18]$. Literature review shows that only two articles have examined the effects of brace on kinetic variables of athletes following ACL reconstructive surgery. Birmingham (2002) showed that using brace would reduce the knee flexor torque in patients after ligament reconstructive surgery with hamstring autograft [8]. However, Risberg et al. (1999) reported that using brace would not create significant changes on kinetic biomechanics variables of athletes following ACL reconstructive surgery through patellar tendon [19].

Review of literature reveals that most studies about the role of brace on the knee joint kinetic have been conducted on athletes without joint damage and also there are inconsistencies between the results of a few studies conducted on athletes with ACL injury after reconstructive surgery. These inconsistencies may be due to the difference in the method of reconstructive surgery or the professional sport level of the athletes. To this end, in this research we attempted to study elite athletes who were in similar athletic field and had undergone similar surgery method. Therefore, in this research and in particular, the effects of using neoprene braces on the knee joint kinetic variables of elite wrestlers who have undergone ligament reconstructive surgery through hamstring tendon autograft, have been examined.

\section{Materials and Methods}

The present research method is quasi-experimental with pretest-posttest design and a control group. In this study, the effect of independent variable (using neoprene knee brace) on dependent variables (kinetic variables, including the ratio of knee flexor muscles torque to the extensor mus- 
cles, average peak torque, maximum power and total work of the knee flexor and extensor muscles) were examined.

The statistical population of the present research comprised best athletes of Free and Greco-Roman style participating in Wrestling Championship of the provinces of Razavi Khorasan, North Khorasan, and South Khorasan three years prior to conducting the research. Also they have undergone ACL reconstructive surgery with hamstring tendon autograft within the past 6 to 18 months. This research was done through in-person interview with coaches of wrestling teams of the three provinces and acquiring comprehensive information regarding members of these teams and also by referrals to the sport medical staff of the said provinces. Statistical sample included 10 persons (average [SD] age: 26.1[2.37] years, average [SD] weight: $78.25[11.32] \mathrm{kg}$, and average [SD] height $174[3.62] \mathrm{cm}$ ) selected through convenience sampling method out of the volunteers participating in this research.

The participants had undergone all post-operation rehabilitation programs supervised by physiotherapist. They regained full range of motion in the operated joint and at least $90 \%$ power of knee flexors and extensors as compared with the healthy knee. All research stages were carefully described to the participants and all volunteers filled out the consent form for taking part in the research. The participants were allowed to drop the test at any stage of the research and for any reason whatsoever. Also, they were assured that their medical and sport records will remain confidential with the researcher.

We used the isokinetic dynamometer device Gymnex model ISO-1 to assess the ratio of knee flexor muscles torque to the extensor muscles, average peak torque, maximum power, and total work of the knee flexor and extensor muscles. First the knee connectors were installed on the device and then the seat backrest of the device was adjusted at 85 degrees. Also in the system software, the test speed for knee flexion and extension was set at $120 \mathrm{deg} / \mathrm{s}$. At first, all participants warmed up by riding a fixed bicycle at $70 \mathrm{rpm}$ with a resistance of $4 \%$ of body weight for 5 minutes. Then, they performed stretching exercises of the thigh and leg anterior and posterior muscles, in static stretches, under supervision of a physical education specialist for 5 minutes. The test was carried out by placing the participant on the special seat of the device with the knees at 90 degrees flexion posture. Before the test, the dynamometer axis was aligned with the knee joint axis. The resistant pad was placed in distal one third of the tibia and the connection site of upper edge of the pad was marked by a marker on the skin so that it remained unchanged in the posttest (Figure

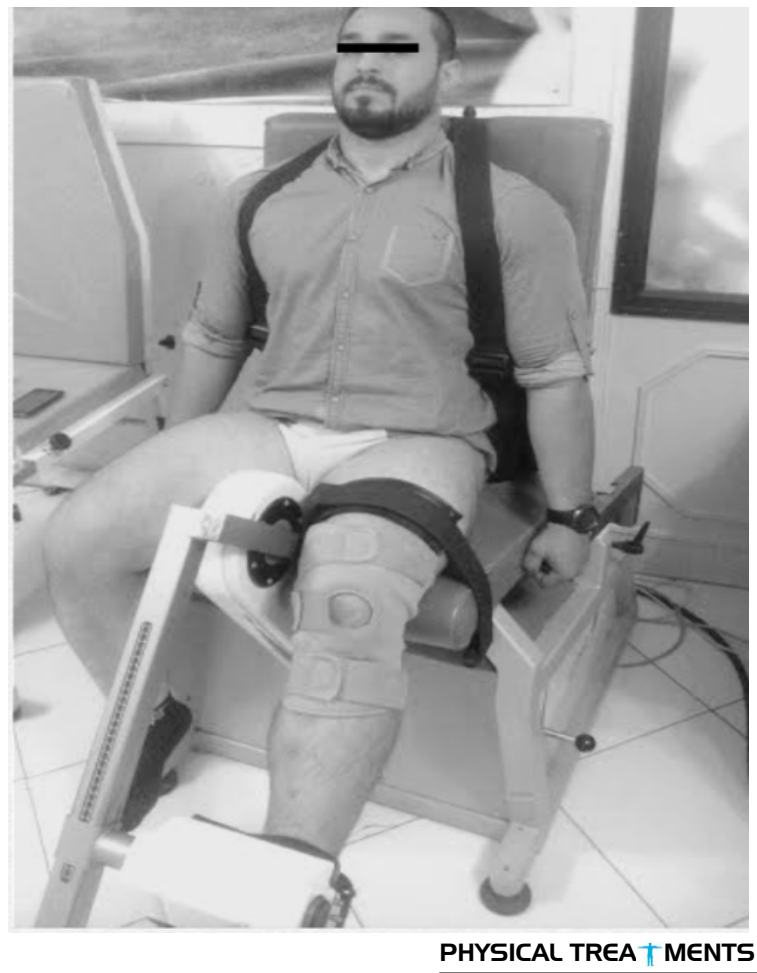

Figure 1. The method of conducting isokinetic test.

1). Each participant carried out three times randomly the test of 5-repetition knee flexion and extension with the brace, and three times without the brace. The participants took 30 seconds rest between each five repetitions and 5 minutes rest between the two modes of with and without the brace. The brace used in this research was neoprene stabilizing knee brace with open patella and two adjustable "ASICS Gel" straps made by the Asics Company. The participants were verbally encouraged to do their best performances. The ratio of the knee flexor muscles torque to the extensor muscles, average peak torque, maximum power and total work of the knee flexor and extensor muscles were recorded for all participants [20].

The descriptive statistics were used to calculate the mean and standard deviation of participants' age, height, and weight and the Kolmogorov-Smirnov (KS) test for determining the normality of data distribution. The results of KS statistical test confirmed the normality of data, therefore, the statistical parametric $t$ test of dependent groups (paired) at the significant level of 0.05 was used to evaluate the effect of the independent variable on the dependent variables.

\section{Results}

Indicators of central tendency and dispersion and the circumstances of distribution of data via KS test demonstrate normal distribution of data (Table 1). The results of statistical $t$ test of the dependent groups showed that 
Table 1. Indicators of central tendency and dispersion and examining the circumstances of data distribution via KolmogorovSmirnov test.

\begin{tabular}{|c|c|c|c|c|}
\hline Variable & Muscles Group & Independent Variable & Mean (SD) & Distribution of Data (KS) \\
\hline \multirow{6}{*}{$\begin{array}{l}\text { Average peak torque } \\
\text { (newton- meter) }\end{array}$} & \multirow{3}{*}{ Flexor } & Without knee brace & $184.30(57.78)$ & 0.994 \\
\hline & & & & \\
\hline & & With neoprene knee brace & $219.30(60.84)$ & 0.989 \\
\hline & \multirow{3}{*}{ Extensor } & Without knee brace & $214.30(66.34)$ & 0.994 \\
\hline & & & & \\
\hline & & With neoprene knee brace & $224.90(76.42)$ & 0.992 \\
\hline \multirow{6}{*}{$\begin{array}{l}\text { Maximum power } \\
\text { (Watt) }\end{array}$} & \multirow{3}{*}{ Flexor } & Without knee brace & $553.50(257.95)$ & 0.935 \\
\hline & & & & \\
\hline & & With neoprene knee brace & $664.50(336.75)$ & 0.937 \\
\hline & \multirow{3}{*}{ Extensor } & Without knee brace & 584(151.13) & 0.227 \\
\hline & & & & \\
\hline & & With neoprene knee brace & $624.20(208.20)$ & 0.681 \\
\hline \multirow{7}{*}{ Total work (Joule) } & \multirow{3}{*}{ Flexor } & Without knee brace & $653(324.80)$ & 0.714 \\
\hline & & & & \\
\hline & & With neoprene knee brace & $688(333.8)$ & 0.683 \\
\hline & & & & \\
\hline & \multirow{3}{*}{ Extensor } & Without knee brace & 717.60(392.38) & 0.464 \\
\hline & & & & \\
\hline & & With neoprene knee brace & $745.20(323.09)$ & 0.352 \\
\hline \multirow{2}{*}{\multicolumn{2}{|c|}{$\begin{array}{l}\text { Ratio of the power of flexor muscles to the } \\
\text { extensor muscles }\end{array}$}} & Without knee brace & $70.80(22.42)$ & 0.809 \\
\hline & & With neoprene knee brace & $79.20(18.12)$ & 0.890 \\
\hline
\end{tabular}

using neoprene knee brace results in significant changes in the average peak torque $(\mathrm{t}=-3.689, \mathrm{P}=0.005)$, maximum power $(\mathrm{t}=-2.286, \mathrm{P}=0.048)$, total work $(\mathrm{t}=-3.925$, $\mathrm{P}=0.003$ ) the knee flexor muscles and also the ratio of the knee flexor muscles to the extensor muscles $(\mathrm{t}=-3.174$, $\mathrm{P}=0.011$ ) in elite wrestlers following ACL reconstructive surgery with hamstring tendon autograft (Table 2). Nevertheless, the results also demonstrate that using neo- prene knee brace does not create significant changes in the average peak torque, maximum power, and total work of the knee extensor muscles $(\mathrm{P}>0.05)$.

\section{Discussion}

This research aimed to study the effect of neoprene knee brace on the knee kinetic variables of elite wrestlers

Table 2. Results of the statistical t test of the dependent groups before and after implementing independent variable.

\begin{tabular}{|c|c|c|c|c|c|}
\hline \multirow[b]{2}{*}{ Variable } & \multirow[b]{2}{*}{ Muscles Group } & \multicolumn{2}{|c|}{ Difference } & \multirow[b]{2}{*}{$\mathbf{T}$} & \multirow[b]{2}{*}{ Significant Level } \\
\hline & & Mean (SD) & $\begin{array}{l}\text { Standard Error of } \\
\text { the Mean (SEM) }\end{array}$ & & \\
\hline \multirow{2}{*}{$\begin{array}{l}\text { Average peak torque } \\
\text { (newton-meter) }\end{array}$} & Flexor & $-35.3(30.258)$ & 9.568 & -3.689 & $0.005^{*}$ \\
\hline & Extensor & $-10.6(35.018)$ & 11.073 & -0.957 & 0.363 \\
\hline \multirow{3}{*}{ Maximum power (Watt } & Flexor & $-11.1(153.562)$ & 48.560 & -2.286 & $0.048^{*}$ \\
\hline & & & & & \\
\hline & Extensor & $-76.2(180.635)$ & 57.121 & -1.334 & 0.215 \\
\hline \multirow{3}{*}{ Total work (Joule) } & Flexor & $-35.9(28.926)$ & 9.147 & -3.925 & $0.003^{*}$ \\
\hline & & & & & \\
\hline & Extensor & $-27.6(182.931)$ & 57.847 & -0.477 & 0.645 \\
\hline \multicolumn{2}{|c|}{ Ratio of flexor muscles' power to the extensor muscles } & $-84(8.369)$ & 2.645 & -3.174 & $0.011^{*}$ \\
\hline
\end{tabular}


after the ACL reconstructive surgery with hamstring tendon autograft. The result of isokinetic tests showed that using neoprene knee brace improved kinetic variables of the average peak torque, maximum power and total work of the knee flexor muscles of wrestlers. These results while confirming the research results of Morteza et al. (2013) and Rebel et al. (2001) demonstrate that the effect of brace on the knee joint kinetic (maximum torque, power and work) mostly affects the function of flexor muscles rather than the extensor muscles, and this is also confirmed by the increase in the ratio of the knee flexor muscles torque to the extensor muscles $[17,18]$. However, results of the present research are inconsistent with the results of Birmingham et al. (2002) study that the differences might be related to gender and levels of athletic activity of the participants.

Since, the hamstring group plays an important role in the stability of the knee joint during vigorous bodily exercises, and some researchers have reported on reduction of power in this group of muscles following ACL reconstructive surgery [21], improvement in the knee flexor muscles is very important for better performance of the athlete after reconstructive surgery [22]. Also since these muscles act as ACL agonist, the improving kinetic variables of these muscles through reduction in the anterior displacement level of the tibia relative to the femur plays an important role in reducing the tension exerted on the ligament and results in lowering the likelihood of ACL re-injury [8]. Although ACL reconstructive surgery improves the mechanical stability of the knee joint, the recovery of knee normal function after surgery is not always satisfactory [23] which is probably due to the feedback of mechanoreceptors and reduction in the muscles reflexive contraction [24]. Because many researchers have emphasized the effect of neoprene braces on improving the knee joint proprioception [2527], it seems that using neoprene brace through increasing sensory inputs to CNS (central nervous system) can affect the muscles function of the injured person, especially the hamstring muscles $[28,29]$. As the dynamic stability of the knee joint while performing sports skills only results from the mutual cooperation of the active forces of muscles and passive resistance of the ligaments, using neoprene brace can affect the active function of the knee flexor muscles through increasing the sensory outputs of the knee joint and besides improving the wrestler's function in skills that require vigorous activities of the knee flexor muscles, reduce the risk of ACL re-injury. However, conducting further studies seems necessary to better understand how brace affects neuromuscular control during sport activities.
Based on the results, using neoprene knee braces improves the function of knee flexor muscles and as a result reduces the rate of pressure exerted on ACL when performing wrestling techniques. Therefore it is recommended that elite wrestlers after ligament reconstructive surgery with hamstring tendon autograft and carrying out rehabilitation program, use neoprene knee braces for improving the flexor muscles function and reducing the likelihood of ACL re-injury. Nevertheless, as the present study only examined the effect of neoprene knee brace on kinetic variables of elite male wrestlers, further studies are needed on athletes of other athletic fields who use neoprene knee brace.

\section{Acknowledgments}

This paper was extracted from the first author's $\mathrm{PhD}$ thesis, Department of Physical Education and Sport Sciences, Faculty of Humanities, University of Bojnord, Bojnord.

\section{Conflict of Interest}

None of the authors declared a personal or financial conflict of interest.

\section{References}

[1] Brownsten B, Bronner S. Functional movement in orthopaedic and sport physical therapy evaluation, treatment and outcomes $.1^{\text {st }}$ edition. New York: Churchill Livingstone; 1997.

[2] Rishiraj N, Taunton JE, Lloyd-Smith R, Woollard R, Regan $\mathrm{W}$, Clement DB. The potential role of prophylactic/ functional knee bracing in preventing knee ligament injury. Sports Medicine. 2009; 39(11):937-960. doi: 10.2165/11317790000000000-00000

[3] Roos EM. Joint injury causes knee osteoarthritis in young adults. Current Opinion in Rheumatology. 2005; 17(2):195200. doi: 10.1097/01.bor.0000151406.64393.00

[4] Rahimi Bashar F. [Clinical examination of knee ligaments and meniscus in wrestlers in the city of Tehran (Persian)] [MD thesis]. Tehran: Tehran University of Medical Sciences; 1999.

[5] Eriksson E. Hamstring tendons or patellar tendon as graft for ACL reconstruction? Knee Surgery, Sports Traumatology, Arthroscopy. 2007; 15(2):113-114. doi: 10.1007/s00167007-0285-0

[6] Miller JP, Vailas JC, Croce RV, Confessore R, Catlaw K. Dynamic analysis of custom-fitted functional knee braces: EMG and brace migration during physical activity. Jour- 
nal of Sport Rehabilitation. 1999; 8(2):109-122. doi: 10.1123/ jsr.8.2.109

[7] France PE, Paulos LE. Knee bracing. Journal of the American Academy of Orthopaedic Surgeons. 1994; 2(1): 281-287. doi: 10.5435/00124635-199409000-00006

[8] Birmingham TB, Kramer JF, Kirkley A. Effect of a functional knee brace on knee flexion and extension strength after anterior cruciate ligament reconstruction. Archives of Physical Medicine and Rehabilitation. 2002; 83(10):1472-1475. doi 10.1053/apmr.2002.35093

[9] Pietrosimone BG, Grindstaff TL, Linens SW, Uczekaj E, Hertel J. A systematic review of prophylactic braces in the prevention of knee ligament injuries in collegiate football players. Journal of Athletic Training. 2008; 43(4):409-415. doi: 10.4085/1062-6050-43.4.409

[10] Ott J, Clancy W. Functional knee braces. Orthopaedics. 1993; 16(2):171-176.

[11] Théoret D, Lamontagne M. Study on three-dimensional kinematics and electromyography of ACL deficient knee participants wearing a functional knee brace during running. Knee Surgery, Sports Traumatology, Arthroscopy. 2006; 14(6):555-563. doi: 10.1007/s00167-006-0072-3

[12] Ramsey DK, Wretenberg PF, Lamontagne M, Németh G. Electromyographic and biomechanic analysis of anterior cruciate ligament deficiency and functional knee bracing. Clinical Biomechanics. 2003; 18(1):28-34. doi: 10.1016/s02680033(02)00138-9

[13] Acierno SP, D'Ambrosia C, Solomonow M, Baratta RV, D'Ambrosia RD. Electromyography and biomechanics of a dynamic knee brace for anterior cruciate ligament deficiency. Orthopedics. 1995; 18(11):1101-1107. PMID: 8559695

[14] Ewing KA, Begg RK, Galea MP, Lee PVS. Effects of prophylactic knee bracing on lower limb kinematics, kinetics, and energetics during double-leg drop landing at 2 heights. The American Journal of Sports Medicine. 2016; 44(7):1753-61. doi: $10.1177 / 0363546516637178$

[15] Mortaza N, Ebrahimi I, Jamshidi AA, Abdollah V, Kamali $\mathrm{M}$, Abas WABW, et al. The effects of a prophylactic knee brace and two neoprene knee sleeves on the performance of healthy athletes: A crossover randomized controlled trial. PLoS One. 2012; 7(11):e50110. doi: 10.1371/journal. pone. 0050110

[16] Baltaci G, Aktas G, Camci E, Oksuz S, Yildiz S, Kalaycioglu $\mathrm{T}$. The effect of prophylactic knee bracing on performance: balance, proprioception, coordination, and muscular power. Knee Surgery, Sports Traumatology, Arthroscopy. 2011; 19(10): 1722-1728. doi: 10.1007/s00167-011-1491-3

[17] Mortaza N, Abu Osman NA, Jamshidi AA, Razjouyan $\mathrm{J}$. Influence of functional knee bracing on the isokinetic and functional tests of anterior cruciate ligament deficient patients. PlosOne. 2013; 8(5):64308. doi: 10.1371/journal. pone. 0064308

[18] Rebel M, Paessler H. The effect of knee brace on coordination and neuronal leg muscle control: an early postoperative functional study in anterior cruciate ligament reconstructed patients. Knee Surgery, Sports Traumatology, Arthroscopy. 2001; 9(5):272-81. doi: 10.1007/s001670100202
[19] Risberg M, Holm I, Steen H, Eriksson J, Ekeland A. The effect of knee bracing after anterior cruciate ligament reconstruction. A prospective, randomized study with two years' follow-up. The American Journal of Sports Medicine. 1999; 27(1):76-83. doi: 10.1177/03635465990270012101

[20] Heinrichs KI, Perrin DH, Weltman A, Gieck JH, Ball DW. Effect of protocol and assessment device on isokinetic peak torque of the quadriceps muscle group. Isokinetics and Exercise Science. 1995; 5(1): 7-13.

[21] Vairo GL. Knee Flexor Strength and Endurance Profiles After Ipsilateral Hamstring Tendons Anterior Cruciate Ligament Reconstruction. Archives of Physical Medicine and Rehabilitation. 2014; 95(3):552-61. doi: 10.1016/j. apmr.2013.10.001

[22] Xergia SA, McClelland JA, Kvist J, Vasiliadis HS, Georgoulis $\mathrm{AD}$. The influence of graft choice on isokinetic muscle strength 4-24 months after anterior cruciate ligament reconstruction. Knee Surgery, Sports Traumatology, Arthroscopy. 2011; 19(5):768-780. doi: 10.1007/s00167-010-1357-0

[23] Bonfim T, Paccola C, Barela J. Proprioceptive and behavior impairments in individuals with anterior cruciate ligament reconstructed knees. Archives of Physical Medicine and Rehabilitation. 2003; 84(8):1217-1223. doi: 10.1016/s00039993(03)00147-3

[24] Mayr HO, Weig TG, Plitz W. Arthrofibrosis following ACL reconstruction? Reasons and outcome. Archives of Orthopaedic and Trauma Surgery. 2004; 124(8): 518-22. doi: 10.1007/s00402-004-0718-x

[25] Van Tiggelen D, Coorevits P, Witvrouw E. The use of a neoprene knee sleeve to compensate the deficit in knee joint position sense caused by muscle fatigue. Scandinavian Journal of Medicine \& Science in Sports. 2007; 18(1):62-66. doi: 10.1111/j.1600-0838.2007.00649.x

[26] Herrington L, Simmonds C, Hatcher J. The effect of a neoprene sleeve on knee joint position sense. Research in Sports Medicine. 2005;13(1):37-46. doi:10.1080/15438620590922077

[27] Brunetti O, Filippi GM, Lorenzini M, Liti A, Panichi R, Roscini $\mathrm{M}$, et al. Improvement of posture stability by vibratory stimulation following anterior cruciate ligament reconstruction. Knee Surgery, Sports Traumatology, Arthroscopy. 2006; 14(11):1180-1187. doi: 10.1007/s00167-006-0101-2

[28] Kapreli E, Athanasopoulos S. The anterior cruciate ligament deficiency as a model of brain plasticity. Medical Hypotheses. 2006; 67(3):645-50. doi: 10.1016/j.mehy.2006.01.063

[29] Hewett T, Myer G, Ford KR. Biomechanical measures of neuromuscular control and valgus loading of the knee predict anterior cruciate ligament injury risk in female athletes: A prospective study. A Prospective Study. American Journal of Sports Medicine. 2005; 33(4):492-501. doi: $10.1177 / 0363546504269591$ 